\title{
Learning to "Brave Up": Collaboration, Agency, and Authority in Multicultural, Multilingual, and Radically Inclusive Classrooms
}

\author{
Alison G. Dover \\ California State University, Fullerton \\ U. S. A. \\ Fernando Rodríguez-Valls \\ California State University, Fullerton \\ U. S. A.
}

ABSTRACT: The Summer Language Academy (SLA) is an innovative and intensive summer program for high-school aged newcomers/new Americans, English learners, and emergent bilinguals, as well as for teachers working with them. In the SLA, students and educators collaboratively explore questions of identity, language, and culture through high-interest texts, arts-based curriculum, and redefinition of teaching and learning as reciprocally shared endeavors. In this article, we examine SLA implementation and impact in two neighboring districts, focusing on the opportunities and tensions that arise when new and veteran educators are challenged to increase their consciousness and capacity regarding multicultural, multilingual, and radically inclusive teaching.

KEYWORDS: emergent bilingual, culturally sustaining, multilingual education, multicultural education, English learner

\author{
Theoretical Framework \\ Research Methods \\ Results \\ Discussion \\ Recommendations \\ Notes \\ References \\ Author Contact
}

Two decades into the $21^{\text {st }}$ century, educators are still looking for ways to meet the academic needs of culturally and linguistically diverse students enrolled in compulsory K-12 educational settings. Despite increased awareness of the importance of using students' cultural and linguistic assets to support academic learning, many educators struggle to implement this vision in the classroom (Annamma, Boele, Moore, \& Klingner, 2013; Howard, 2014). While this tension impacts all students, the implications are especially significant for students from historically marginalized groups, including immigrants (Rodríguez-Valls, 2016). Newcomer students, and especially those who do not yet have academic fluency 
in English, often struggle to feel academically, socially, and relationally connected at school and in their community (Yeon Kim \& Suárez-Orozco, 2014). In addition to linguistic barriers, many newcomer students also face significant social and economic pressures, including high levels of poverty, unwelcoming social or political climates, and experiences of racism and discrimination (Choi, 2013; Suárez-Orozco, Pimentel, \& Martin, 2009). Research demonstrates that culturally and linguistically responsive teaching has a positive impact on students', especially marginalized students', academic, social, and attitudinal outcomes (Aronson \& Laughter, 2016; Dover, 2009; Lee, 2010; Sleeter, 2011). However, institutional forces in schools, including pressure towards standardization, monolingualism, and test-based accountability, can trouble teachers' efforts to center the immediate, localized, and situated needs of their students (Sleeter, 2011). This results in the marginalization of culturally and linguistically responsive teaching in K-12 and teacher education programs alike, undermining new and experienced teachers' development of the autonomy, agency, and self-efficacy necessary to enact social justice-oriented change (see Dover, Henning, \& Agarwal-Rangnath, 2016).

In this article, we examine how participation in an innovative districtuniversity-community partnership, the Summer Language Academy (SLA), prepares educators to re-imagine public education as created with and for students historically marginalized in our classrooms. In the SLA, students, preservice teachers, and veteran educators work collaboratively to explore questions of identity, language, and culture, and to redefine teaching and learning as reciprocal, shared endeavors. Throughout, educators are re-socialized to prioritize the maintenance and development of newcomer students' complex linguistic repertoires and also to gain practice creating opportunities for students to use English both in informal and academic settings. Collectively, these skills prepare teachers to nourish students' ability to acquire high levels of language proficiency in English as well as achieve college-level content readiness (Carhill, SuárezOrozco, \& Pàez, 2008; Kibler, Valdés, \& Walqui, 2014).

In the following pages, we present the theoretical framework for and analyze implementation of the SLA in two neighboring school districts. Throughout, we focus specifically on the opportunities and astrictions, or tensions, that arise when new and experienced educators are challenged to increase their consciousness and capacity regarding multicultural, multilingual, and radically inclusive teaching. We conclude with recommendations for professional learning to prepare educators to teach and learn effectively within shifting linguistic and cultural landscapes.

\section{Theoretical Framework}

Research suggests that newcomer/new American students are too often exposed to programs that neither value their cultural and linguistic richness nor embrace their identities as assets for their learning (Gee, 2004). Moreover, school districts struggle to design and implement programs that both affirm newcomer 
students and also empower them to use their social and linguistic capital as springs to expand their social mobility (Fránquiz \& Salinas, 2011; Freire \& Valdez, 2017; Mitchell, 2012; Salinas, Sullivan, \& Wacker, 2007).

The SLA was designed to reinforce what research highlights: the importance of culturally and linguistically responsive, [bi]literacy-rich instruction that invites and validates the cultural and linguistic experience of newcomer/new Americans (Creese \& Blackledge, 2010; Genesee, Linholm-Leary, Saunders, \& Christian, 2005). When students learn with educators who have strong understandings of culturally and linguistically responsive pedagogy, they tend to develop a deeper sense of their own identity, which is correlated with higher levels of academic performance (Borrero \& Sanchez, 2017; Lopez, 2016). By building an educational space where educators and students are taught to value what each participant brings to the classroom, the SLA creates a Zone of Cultural Comfort (ZCC) (Rodríguez-Valls, 2009) where each community member assumes the role of a knowledgeable other (Vygotsky, 1986).

Conceptually, the SLA is grounded in theories and practices of translanguaging, in which educators embrace the literacies and discursive practices of multiple languages, model linguistic fluidity and risk-taking, and function as linguistic co-learners alongside their students (Flores \& García, 2013). García and Seltzer (2016) define translanguaging pedagogy as "the strategic deployment of a speaker's full linguistic repertoire to learn and develop their language repertoire and at the same time work toward social justice by equalizing positions of learners" (p. 23). In the SLA, educators share the pieces that constitute their individual linguistic repertoire (i.e., languages they speak and various registers used within these languages), and ask students to interrogate their own individual linguistic repertoires. As students reflect, teachers strategically and intentionally highlight the importance of languaging through the three modes of communication: interpersonal (understanding who they are), interpretative (exploring who they want to be) and presentational (sharing with others). This interweaving of multiple linguistic repertoires and communicative modes "creates a social space for the language user [teachers and students] by bringing together different dimensions of their personal history, experience, and environment; their attitude, belief, and ideology; their cognitive and physical capacity" (Wei, 2018, p. 23).

\section{Rethinking the Role of Languages in the Classroom}

SLA faculty undergo comprehensive professional development to resocialize them as transformative educators. In addition to training related to translanguaging pedagogy, faculty attend sessions on co-teaching, co-planning, and inquiry-oriented teaching. Throughout, we emphasize strategies for creating "humanizing classrooms" (Paris \& Alim, 2017) and engage faculty in team-building activities, including the creation and sharing of poetry, narrative, and art. Faculty examine their own educational socialization, both individually and as part of 
culturally and linguistically diverse teams, within which monolingual and bilingual educators work cooperatively to draw from each other's linguistic expertise and repertoires.

During the SLA, educators and students analyze how languages and cultures collide within focal texts, as well as within the classroom itself. Throughout, they interrogate how students' literacy and linguistic repertoires in their native language(s) (L1) can provide a foundation when acquiring English (L2). However, rather than seeking to shift students from L1 dominance to L2 dominance, in the SLA we center students' development as emergent bi/multilinguals. By framing students' first language(s) and emergent bilingualism as an asset, the SLA positively reinforces students' sense of identity and agency (Valenzuela, 2016). This enables students to experience their integration into U.S. schools and societies, and their development of academic English, as an additive, rather than subtractive, experience.

Additionally, as faculty model the deconstruction and co-construction of language and learning, they are forced to interrogate their own strengths and areas for growth as culturally and linguistically responsive educators. Faculty are coached to be transparent about this co-learning and to model mutual respect and appreciation for the "knowledgeable other" as a step towards encouraging students to examine patterns of social, linguistic, and cultural dominance. Students, in turn, re-imagine themselves as co-creators of educational spaces and develop the voice and agency necessary to "speak up" for their linguistic, cultural, and academic priorities.

\section{Inquiry-Based, Student-Driven Curriculum}

The SLA draws upon research regarding student-centered, culturally responsive, and socioculturally-centered teaching; collectively, these have been proven to have a positive impact on student achievement, participation, motivation, self-esteem, sense of belonging in educational environments, identity development, and attitudes about learning, especially among racially and linguistically marginalized students (e.g., Aronson \& Laughter, 2016; Dover, 2009; Gay, 2000; Ladson-Billings, 1995; Oyserman, Harrison, \& Bybee, 2001; Sleeter, 2011). It is also aligned with research regarding the import of social and interactional literacies and multicultural perspectives as central to students' literacy development (NCTE, 2007), irrespective of students' mono- or multilingualism.

In addition to supporting student achievement, curricular processes in the SLA are designed to be culturally sustaining (Paris \& Alim, 2017) within and beyond the classroom walls. SLA faculty are encouraged to use culturally relevant (Ladson-Billings, 1995) and responsive pedagogy (Gay, 2000) to reconceptualize teaching and learning within a liberatory third space (Gutiérrez, 2008). Throughout, we frame the SLA as an opportunity for students and educators to 
explore multilingual, multicultural, and radically inclusive teaching and learning outside of the strictures of institutionalized schooling.

Table 1.

SLA Skeleton Curriculum

\section{Summer Language Academy Curriculum Framework}

Week 1: Who am I?

- Writing pre-test: Who are you?

- Read and create odes about identity, and participate in a spoken word (ode) contest

- Begin reading \& viewing diverse texts about identity \& identity representation

- Introduce culture collages

- Performance tasks: Self-portrait and ode

Week 2: Exploring family \& culture

- Draw family portraits depicting their own family

- Write about and create video and visual collages related to their family \& culture

- Examine identity, culture \& characterization in literature, analyzing how identity is represented across print \& film versions of texts

- Performance task: Family portraits \& digital cultural collages

Week 3: Understanding community

- Explore the characteristics of community in literature and their lives

- Develop skits to represent aspects of community as depicted in literature

- Create brochures depicting their community

- Performance task: Students create labels, slogans or tags to represent key aspects of their community

Week 4: Understanding myself within my community

- Writing post-test: Who are you?

- Analyze how authors \& directors used literary and visual images to convey meaning

- Performance task: Students create a community mural / graffiti wall that represents their individual and communal values and ideas

2017 Focal Texts: Antoine de Saint-Exupéry's The Little Prince, Gary Soto's Neighborhood Odes, Sandra Cisneros’ The House on Mango Street, Gene Luen Yang's American Born Chinese, and student-selected poetry and music

This vision is woven throughout all aspects of the SLA, from pre-program professional development through the presentation of culminating projects. Prior to the SLA, faculty reflect upon their own identities and the norms present within their respective school communities and then participate in a visioning process in which they reimagine school as affirming and culturally robust. Within the SLA, we invite educators to discard policy and pedagogical practices that silence, marginalize, or otherwise confine students' humanity, and instead create classroom communities that authentically reflect the personal, cultural, and 
linguistic identities and values of their participants. While each year's SLA features a skeleton curriculum and set of core texts (see Figure 1), educators are supported in interrupting and re-visioning any programmatic element that privileges teachers' authority over students' autonomy. In so doing, we seek to shift both educators' and students' approach to agency and authority in the classroom, thus resocializing them to build collaborative educational communities.

In the SLA, educators model this interruption by developing classroom routines that reflect students' needs for food, space, sound, silence, and breaks; using their own identity and experience to model key projects (e.g., by creating and sharing verbal and artistic renderings of their own multiple identities before asking students to do the same); and positioning students' languages, families, cultural traditions, and artwork as authoritative "texts." Students work collaboratively to define, customize, and complete final projects, determine how to share their work with other classes and their families, and make recommendations to improve teaching and learning during the academic year. Thus, the SLA engages students as key stakeholders within the classroom and community at large, while simultaneously challenging educators to unlearn and reconstruct their approach to teaching, learning, and culturally responsive classroom leadership (Fraise \& Brooks, 2015).

\section{Research Method}

The data presented in this paper were collected during the second year of SLA implementation. In Year 1, our primary focus was on the impact of the SLA on students; by Year 2, we had shifted our analysis to examine how the SLA impacted teachers and school communities. In keeping with our overarching emphasis on collaborative inquiry, our research is informed by principles of constructivist grounded theory, which centers the interpretive construction of theory through multilayered and sustained interactions among researchers, participants, data, and research practices (Charmaz, 2006). All SLA faculty were invited (but not required) to participate in this research, and research personnel were embedded in the site throughout the program. The research team attended daily debriefing sessions among program faculty, shared observations with faculty, and engaged faculty as co-theorizers in making meaning of emergent trends in the data.

Multiple members of the research team reviewed and coded qualitative, open-ended, and observational data. Throughout analysis, we used focused coding and memo-writing (Charmaz, 2006; Creswell, 2007) to interpret the data and our evolving framework. This enabled us to explore emergent trends and multiple layers of meaning within participants' responses and to trace the evolution of our theoretical model. As we began to sort our initial codes into categories, we revisited transcripts and field notes to identify examples and quotes related to each phenomenon; we also wrote interpretive memos that explored how each theme 
emerged at each of our two SLA sites and any contextual factors that may have impacted program processes or outcomes.

\section{Data Sources}

The data presented in this paper were drawn from formal (pre/post) openended surveys of faculty, analyses of SLA faculty members' written reflections (gathered at seven points throughout the program), transcripts of daily debriefing sessions (approximately half of which were audio recorded), and field notes of researchers in two neighboring districts $(A$ and $B)$ that implemented the Summer Language Academy in 2017. Across these two sites, the SLA enrolled 146 high school students and 24 faculty (including 7 district teachers, 4 instructional assistants, 8 preservice teachers, 3 district administrators, and 2 university faculty); one preservice teacher (Sandra) taught in both sites. Students included recent immigrants, refugees, undocumented students, and "long term English learners," who came from more than 20 countries, collectively spoke 17 languages altogether, and had varying levels of literacy in both their L1 and L2. In this paper, we foreground faculty members' analyses of their experiences, and do not draw data from students or parents.

Collectively, the SLA faculty spoke seven languages (though some were monolingual in English); approximately two-thirds of SLA faculty identified as bicultural. Some SLA faculty members were recruited into this program by the district or university partners while others were appointed by the district on the basis of seniority; thus, faculty members entered the SLA with varying levels of conceptual and practical experience with culturally and linguistically sustaining teaching.

\section{Results}

The data revealed an array of social and ecological factors that impacted faculty teaching and learning within the SLA. These included faculty members' divergent visions of culturally and linguistically responsive instruction, prior professional socialization as well as two related sub-themes that emerged during the course of the study, and navigation of professional and linguistic dominance within and beyond the classroom.

\section{Divergent Visions of Culturally and Linguistically Responsive Teaching}

The instructional teams in the SLA were "uneven" by design, in that each was composed of educators who were not typically positioned as equals within school settings. Moreover, each team included both monolingual and multilingual 
educators, as well as educators with expertise related to different aspects of the SLA curriculum (e.g., art, literacy, language, social science, etc.). Our intention was to create opportunities for educators to learn to work collaboratively across institutional and linguistic boundaries and to develop the skills necessary to model these practices in the classroom. However, despite faculty members' stated commitment to this vision, in practice they sometimes struggled to overcome their own adaptation to the norms of institutionalized schooling.

We anticipated that faculty would enter with diverse trajectories as culturally and linguistically responsive teachers. Nevertheless, we were surprised when preprogram questionnaires revealed that some teachers saw the teaching of "pronunciation" and "correctness" as important outcomes, and others struggled to provide concrete examples from their own practice. Sandra ${ }^{1}$, a preservice teacher, offered the following example of her previous experience as a culturally responsive educator in an unrelated summer program:

One of my favorite lessons was about introducing the students to various mythologies. The students were prompted into a discussion about how the work was translated, and as we compared all the stories and their similarities, I got to learn from my students their perspective of the story, and how they felt it didn't represent the stories they had been told as a child.

By contrast, Calixto, a district-designated "teacher of English Learners," simply described responsive teaching as "teaching about the family and the different roles culture and nationality play within the family," and Macarena, a preservice teacher assigned to District $A$, indicated she had not "had the pleasure to observe something like that [culturally or linguistically responsive teaching] in any of [her] classroom observations." In addition to revealing teachers' variable levels of fluency in culturally and linguistically responsive teaching, pre-program surveys also foreshadowed some of the tensions that would emerge later in the program. For example, while most educators applied to the SLA in the hopes of increasing their capacity as teachers of newcomer and emergent bilingual students, others (like Calixto) would struggle to unlearn preexisting "knowledge" of multicultural and multilingual education.

However, despite variance in their initial approach to culturally and linguistically responsive teaching, as the program evolved, faculty demonstrated an increasingly comprehensive vision of responsive instruction. During Week 1, faculty members highlighted goals of "getting to know" students and "making them feel good and safe." Later in the program, teachers began to focus less on affirming their diverse students and more on ways to "deepen" conversations about structural factors related to identity, culture, and language. Multiple teachers focused on themes of "struggle" in literature and the parallel struggles students faced in their country of origin, community, or classroom. District A teacher Tadea, for example, said her favorite part of Week 1 was "seeing a team of four students: Korean, Arabic, Chinese, and Spanish-speaking, standing up around a quad table with their arms around one another, peace signs up, taking a selfie. THIS IS WHAT IT IS ALL ABOUT!" By Week 3, however, her goals had evolved: 
Because we were on the topic of struggles this week, we tried an activity where the students draw their picture on the outside of a foldable along with words that are "above the surface" words. Inside the foldable, they were to free write about a specific struggle in their life. I was awestruck when I saw the level of detail they included in their writing. They all opened up and explained to us the struggles they are facing, and it really painted an emotional picture in my mind. These kids are braving up, and I love that.

Emphasis on the interrelationship among self-disclosure, classroom community, and academic learning was a common theme throughout educators' journals, as well as their final reflections.

Post-program analyses revealed that the program led to an increased appreciation for the value of culturally and linguistically responsive teaching as well as a greater sense of efficacy as a responsive educator. District B teacher Luciana framed this as necessary in light of social and political tensions in her district, calling it a "duty" for teachers to "value all languages and cultures especially at a school where it is so divided." Likewise, District B preservice teacher Tatum concluded:

This program offers students...the opportunity to feel included and be themselves and develop strong connections to their school community and peers....Students in the program were initially introverted and nervous to speak in the classroom, but by teachers using culturally responsive teaching students were able to feel more comfortable and confident in the classroom environment and grow academically.

The predisposition to work with and learn from all students was a common trait among SLA educators. However, even with this shared commitment to being responsive to students' cultural and linguistic richness, some educators struggled to leave behind institutionalized norms of professional or linguistic dominance. In the following sections, we examine some of the opportunities and astrictions that arose as educators were challenged to approach teaching and language differently. Throughout, we explore interactions that led to "productive tensions" within and beyond the classroom.

Unlearning professional socialization. hooks (2003) argues that "to build community requires vigilant awareness of the work we must continually do to undermine all the socialization that leads us to behave in ways that perpetuate domination" (p. 36). This vision guides the SLA, as we seek to disrupt the hegemonic practices that silence, marginalize, and oppress the voices of culturally and linguistically diverse students. Throughout the SLA, faculty are challenged to be collaborative, non-hierarchical educators who model linguistic fluidity and pedagogical risk-taking. Unlike traditional classrooms, where "teachers teach and students learn," in the SLA teachers and students are co-learners; teachers do each assignment alongside students, reveal their own linguistic and cultural histories, and share authority with each other and students.

In addition to reconsidering their interactions with students, SLA faculty are also pushed to examine other types of power differentials at play within the 
classroom. In the SLA, each educator, regardless of her/his official "status" (as a preservice teacher, in-service teacher, or instructional assistant), content area expertise, or linguistic fluencies, is presented as "Teacher" and expected to fully and actively participate in the design, implementation and evaluation of teaching and learning practices. When building the program, we were fully aware of the tensions that this horizontal leadership could create, especially for credentialed teachers. However, we were hopeful that all educators would benefit from collaborative leadership and the opportunity to build authentic, reciprocal relationships with their colleagues and students. Palmer (2007) defines this capacity as preparing teachers to "weave a complex web of connections among themselves, their subjects and their students so students can learn to weave a world themselves" (p.11).

Throughout the faculty recruitment and training process, we framed the SLA as an opportunity to affirm students' cultural and linguistic identities, celebrate multilingualism, and prepare newcomer students and Emergent Bilinguals to see themselves as co-creators of educational spaces. All SLA faculty expressed a stated commitment to these goals both during their interviews and throughout preprogram professional development. Nevertheless, once the program began, faculty sometimes struggled against their own professional socialization, creating dissonance between their existing practices and the collaborative, emergent curricular and pedagogical processes centered in the SLA. This manifested through tensions within teams, as well as comments during weekly reflections or debriefing sessions related to educators' desire to "shift to more English," get assistance with "translation" (rather than use translanguaging pedagogies), control students' behavior, or avoid "too much art and conversation" rather than academic writing in English.

In the section that follows, we examine the productive disruptions that emerged as faculty were challenged to learn from and share authority with colleagues with different levels and types of professional experience, varying degrees of bi/multiliteracy, and diverse disciplinary and pedagogical emphases. Rather than seeing their struggles as failures, we consider these tensions central to the work of the SLA as teachers have the types of professional learning experiences that prepare them to bring collaborative, student-driven, and transformative teaching back to their school sites.

Sharing authority. For many faculty, the SLA's emphasis on humanizing education by bringing our "whole selves" to the classroom was both unfamiliar and precious. During Week 1, for example, Karina described her team's efforts to cultivate "symbiotic relationship[s]" where students "trust us with their stories and self-exploration as we trusted them with our experiences and identity exploration. By everyone sharing, everyone grows in their journey." SLA faculty saw the positive impact that their efforts had on students, describing their "pride" as students were "brave" and shared their interests, lives, and cultural and linguistic journeys. Teachers also experienced self-disclosure as unfamiliar and uncomfortable; in Week 3, Sandra noted that "sharing who I am daily is proving exhausting. I'm not sure I've ever been this honest with myself, much less with 
others. It has been emotionally draining." Overall, educators described this reconceptualization of the relationship between teacher and student as among the most impactful elements of the SLA.

However, as teachers adapted to the rhythm and emphases of the SLA, they also grappled with tensions between their stated values and the realities of teaching cooperatively. For example, while most SLA faculty highlighted coteaching as one of the most beneficial aspects of the SLA model, other teams had difficulty translating this vision into practice. Karina, a District A preservice teacher, underscored the intentionality characteristic of productive collaborations:

This week, my team has worked together like a ladder, as three separate identities coming together. As two legs and a rung that support each other to build towards climbing higher and higher. Since we are able to work together, we then provide strength and support to our students to climb to their next level and beyond. As a team, we have established the respect of actively listening to each other's ideas and making sure that we equally have a role in the classroom.

As the SLA progressed, District B preservice teacher Teo continued to highlight the importance of communication and co-learning as central to his team's growing efficacy

The teachers are getting along great. As we learn each other's styles, the co-teaching has been running smoothly without needing to plan out every minute. However, it is still important to clearly assign responsibilities for specific parts of the day's lesson.

Overall, approaches to mindfulness and curiosity were central themes among the most effective teams.

By contrast, three teams struggled with shared leadership and collaboration. In these cases, one or more team members approached collaboration through the lenses of efficiency or authority, rather than with curiosity about their colleagues' strengths and perspectives. Guillermo, a District A teacher, offered this summary of his perspective:

Diffusing responsibilities among three adults in a classroom has its pros and cons. Who takes the lead? What if two people disagree as to content, delivery, or student activities?...Also, what is the role of an intern? Instructional Assistant? Credentialed Teacher? Are the intern and credentialed teacher equals? I feel that having all students view the adults as "teachers" is important, but it's an important opportunity for interns to understand that they are not experienced, credentialed teachers.

Unsurprisingly, this approach to navigating collegial relationships did not cultivate a positive dynamic within teaching teams. In reflecting on her experience with co-teaching, Monique (the preservice teacher on Guillermo's team) said, "We never developed that kind of [collaborative] relationship. From the very start, I felt very left out since they [Guillermo and the other educator] knew each other for a long time and had a great relationship among themselves." Overall, Monique, who 
was bilingual but did not speak a third language used frequently in her classroom, saw herself both a professional and linguistic outsider within her team.

While Monique and Guillermo's team never fully actualized the vision of shared leadership, their instructional tensions were rarely visible to students or outside observers. For one team, however, patterns of dominance undermined the experience of faculty and students alike. Over the course of the program, the experience of this team could at times be described as grueling, as District B teacher Calixto attempted to exert dominance by undermining or belittling the contributions of his colleagues. His colleagues reported cases where he "overruled" their instructional decisions, contradicted them in front of students, and dismissed their efforts to affirm students' multilingual or arts-based communications.

For Calixto's co-teachers, who included Sandra, a preservice teacher who was a member of a cohesive and collaborative team in District $A$, the tensions within the team were disillusioning and dispiriting. Sandra described her efforts to apply her learning from District $A$ to her interactions with Calixto, but ultimately considered their differences irreconcilable:

I tried this week to focus in on what I could learn from my partners, on remaining positive about working as co-teachers. What I learned is that the way we each interact with our students is so vastly different, and our philosophies of language acquisition may not be reconcilable at all.

Sandra's reflection underscores the complexities that emerge when we attempt to disrupt fundamental practices related to teaching and learning. The tensions experienced by these teams highlight not only the challenges of learning to share authority, but also hegemonic patterns of linguistic and discursive dominance.

In what follows, we examine how educators and students experienced and sought to interrupt linguistic dominance in the classroom.

\section{Navigating Linguistic Dominance}

The second major theme that emerged from this study relates to faculty navigation of linguistic dominance in the SLA context. Students in the SLA spoke 17 languages, while SLA faculty spoke seven; approximately two-thirds of SLA faculty identified as bilingual and bicultural. However, the majority of students (54\% in District A and $84 \%$ in District B) spoke Spanish; no other language was spoken by more than $13 \%$ of students, and several languages were spoken by only one student. This led some faculty to raise concerns about whether the SLA reproduced patterns of linguistic dominance. In this way, faculty grappled with familiar tensions within the bilingual education community: (a) how educators can affirm, and equally value, all the components of students' linguistic repertoire, and (b) how faculty can effectively navigate the discomfort of community members faced with the disruption of their own linguistic dominance. 
Despite their struggles with the role that students' multidimensional linguistic repertoire "should" play in the classroom, SLA faculty demonstrated creativity and compassion in their navigation of linguistic tensions. One of the strategies faculty used to create translangauging spaces was the design of multilingual walls related to key concepts and vocabulary words. Students and teachers worked together to translate these words into all languages represented in the classroom. This cooperatively effort enhanced the linguistic repertoire of each student by adding the words on the target language, English, as well as learning words in all the "minority languages." SLA students and faculty took the risk of building "emancipatory and transformative promise of heteroglossic practices and pedagogies" (Horbenger, 2013, p. vii) to eliminate the prevalence of monolingual and English-Only discourses.

With the occasional exception of Calixto, teachers consistently encouraged students to utilize all of their linguistic repertoires when completing assignments. For example, students in the SLA complete a pre- and post-assessment in which they respond to the prompt, "Who are you?" Most students' pre-assessments were written in a single language, while their post-assessments drew upon their multilingual repertoires, resulting in longer and more complex analyses of their multiple social, cultural, and linguistic identities. This speaks to educators' success in supporting students in considering how they can convey their thoughts most effectively. Overall, teachers sought to establish and create translanguaging spaces that validated and celebrated students' dynamic and complex linguistic repertoires; teachers then worked with students and district personnel to translate student work as necessary.

SLA faculty were vocal regarding their efforts to understand and re-imagine linguistic norms in the classroom. During Week 1, for example, Karina noted:

We also took a linguistic inventory and recognized that we run the risk of our Spanish speaking students dominating the classroom since we have 15 Spanish speakers out of 22 students. Therefore, we as team discussed how we want to ensure that each student's' language and culture is equally represented, valued, and affirmed. We want to encourage all of our students to feel free to express themselves in both English and their native language/s.

Rather than reproducing the patterns of linguistic dominance common in Englishmajority classrooms, Karina's team sought to identify tensions and build paths of linguistic inclusion for all students.

This commitment was a common theme, although building safe and brave linguistic spaces for all SLA students was a process filled with successes and failures. This was especially pronounced in District $B$, where the vast majority of students (and approximately two-thirds of educators) were fluent speakers of Spanish. At the end of Week 1, Luciana (District B) noted that "[we are] still trying to figure out how to include ALL students not just Spanish speaking in activities," while Teo focused on the evolution of his classroom's linguistic culture: 
There is a Spanish dominant culture in the room. The students that are not Spanish speakers are either intimidated or feel left out....Vietnamese student Mai looks lonely at her table with three girls conversing in Spanish [but by day 4, she] looked a little more comfortable and was having a little bit of conversations with other students. On day 3 , it is nice to see the Spanish-speaking girls interact with Dalal, the Arabic speaking student. They asked Dalal how to say mother in Arabic. The Spanish-speaking students were encouraged to speak English as much as they can and did exactly that.

As the SLA progressed, faculty continued to grapple with their own strengths and limitations as multilingual teachers and teachers of multilingual learners. Mia, a bilingual [Spanish] teacher in District A, described this selfanalysis, noting that she "struggled with limiting my language and utilizing SDAIE [Specially Designed Academic Instruction in English] techniques instead of speaking Spanish the entire time." Others, like Geremias, highlighted their monolingualism as a barrier when working with SLA students: "Some of the challenges I encountered was that I only spoke one language, English, and that held me at a disadvantage sometimes with the Spanish-speaking students because I couldn't fully communicate with some of them."

Despite their unremitting effort to overcome these challenges, some SLA faculty claimed that their biggest test was to build a linguistic inclusion that could eliminate silos and isolation within the classroom. Sandra's final reflection illustrates this tussle:

The biggest challenge I found was trying to keep all languages and students included in the classroom. The Spanish speakers wanted to dominate the classroom, and I think the non-Spanish speakers often felt isolated, separated from the rest of the class.

Overall, it was striking how many faculty stressed the perceived imbalance between Spanish speakers and students whose first language was other than Spanish. This is especially noteworthy when framed in contrast to classroom observations, student reflections, and student exit surveys, which never noted concerns about Spanish dominance. We also found that linguistic tensions were named primarily by faculty who were themselves speakers of non-dominant languages, highlighting the value of insider/outsider perspectives on discursive practice and classroom climate.

\section{Discussion}

Initially designed as a program to promote positive academic and relational outcomes among a dramatically underserved student population, the SLA is emerging as an opportunity to understand the complex dilemmas that impact broader efforts related to multicultural, multilingual, and social justice oriented education. Throughout the SLA, educators strategically and intentionally analyzed 
the role languages could play to either interrupt or reinforce linguistic inclusion. Liggett (2012) underlines the fact that "teachers can play an important role in mediating the social dynamics of the classroom as a way to foster universal respect and egalitarian reciprocity" (p. 6). It is clear that SLA faculty saw linguistic egalitarianism as a central element of their work in the classroom and utilized a broad array of curricular, pedagogical, and discursive practices to nourish that vision. Moreover, the structure of the SLA prepared teachers to continuously rerevaluate their linguistic strengths, deficits, and capacity to differentiate and adapt teaching and learning to meet the needs of all students.

For some faculty, the SLA was an opportunity to truly reconceptualize teaching and learning in a new ecology. Using students' native language as a springboard, these faculty supported additive second language acquisition processes in which both languages have equal levels of functionality, value, and status. These educators intentionally and strategically dismantled monolingual paradigms that disfranchise and colonize students under the guise of "acculturation" and embodied principles of transcaring (García, Woodley, Flores, \& Chu, 2012; Wiemelt \& Welton, 2015) in their robust responses to the fluid ethnolinguistic identities of their students. Thus, they experienced the SLA as radically transformative; in the words of Monique, "If I could, I would teach in this program until the day I die." In other cases, however, faculty struggled to navigate the complexities of linguistic dominance, institutional culture, and internalized notions of "effective" teaching and learning. For these teachers, the SLA offered but a glimpse into the dreams, possibilities, and necessity of just and equitable public education.

Our analysis also raised significant questions for us as researchers and teacher educators. In addition to highlighting the importance of explicitly preparing teachers to interrupt internalized patterns of authority, the SLA reveals the shifting context of multicultural and multilingual education. Just as we appreciate faculty members' attention to perceived linguistic dominance within the SLA, we also wonder whether those same educators voice similar concerns when teaching in English-dominant classrooms. Faculty members' reflections made us ponder how we as educators have to understand new ecologies in which English is neither the dominant language nor the vernacular one, as well as how faculty members' own linguistic identities informed their approach to multicultural, multilingual, and inclusive education. Michael, a monolingual pre-service teacher who served as a research assistant throughout this project, offered insight into this question when, during pre-program professional development, he raised the concern that he "would be made to feel that his monolingualism was a deficit in this program." As researchers, we found his comment striking, especially since a core tenet of the SLA is that monolingualism is always a deficit; moreover, we explicitly name it as such, even as we acknowledge the limited bilingualism of one of the authors of this paper. Thus, despite Michael's stated commitment to the vision and values of the SLA, his willingness to publicly raise concerns about his own linguistic comfort underscores the normalization of English dominance in school settings, as well as the degree to which even well-intentioned English-speaking faculty prioritize their linguistic comfort over their students' linguistic identities and needs. 
We wonder about the degree to which actual or perceived linguistic dominance impacted tensions within teams, as educators' identities as mono/bilingual and mono/bicultural impacted their approach to linguistic and discursive fluidity. As teacher educators, our daily practice centers the imperative to prepare pre- and in-service teachers to enact multicultural, inclusive, and justiceoriented pedagogy. This study offers insight into not only the curricular, pedagogical, and policy processes associated with culturally and linguistically responsive education, but also into key opportunities and tensions of implementation. Based on our analysis and the lessons learned through this project, we offer the following recommendations for continuing to nourish capacity building experiences for teachers of immigrants, English learners, and emergent bilinguals.

\section{Recommendations}

Blankstein, Noguera, and Kelly (2016) argue that "if we want to create schools where all the students have the opportunity to be challenged and stimulated and where all the talents can be cultivated, we need a different paradigm to guide our schools" (p. 14). Our experience underscores the critical importance of provoking paradigm shifts not only in our schools, but also in the ways teachers are socialized into their profession. We echo calls for professional learning experiences that require educators to become mindful of and analyze dilemmas of practice (Freire, 2005; Gorski, 2013), collaborate fluidly with diverse stakeholders (Heifetz, Grashow, \& Linksy, 2009), and use their professional agency to develop and implement responses (e.g., Dover, 2018). Like Stillman (2011), we see value in provoking "productive tensions" (p. 134) in order to prepare educators to navigate the complexities of multicultural, multilingual, and radically inclusive teaching within and despite normative educational settings.

The structure of the SLA reflected the vision of the program as collaborative and capacity-building: we adopted a wraparound professional learning model, in which all faculty participated in comprehensive pre-program professional development as well as daily small and large group planning and debriefing sessions. While this was effective at orienting faculty to SLA pedagogy and coaching them in the analysis of student learning, some SLA faculty nevertheless prioritized technical (curricular and pedagogical) aspects of multicultural and multilingual education over our stated goals of thinking, collaborating, and teaching differently. We see a need for increased emphasis on professional development that not only models critical, collaborative, and student-centered practices, but also provokes and prepares educators to navigate cultural, linguistic, and hierarchal tensions. We see much potential in frameworks for critical professional development (CPD) that use cooperative dialogue, community building and shared leadership to meet the critical, social justice-oriented needs of teachers (Kohli et al., 2015). In addition to holding faculty accountable to their vision of equitable, mindful and just teaching (Kohli et al., 2015; Picower, 2011), such models can help 
teachers increase their knowledge of and empathy for newcomer/new Americans and their migratory experiences, specifically in terms of educational needs, family struggles and concerns, and building meaningful relationships in the classroom (Chapman \& Hall, 2016; Powell et al., 2016).

Throughout the SLA, we were also struck by the understanding that in order to approach the teaching of language differently, educators must approach language differently. The patterns of linguistic dominance, and fears of linguistic dominance, that emerged during the SLA revealed not only tensions across faculty members' linguistic and cultural lenses but also the pervasiveness of monolingual ideologies in educational spaces. Thus, we call for increased opportunities, and requirements, for pre- and in-service educators to experience the linguistic and discursive fluidities of translanguaging (Mazak, 2017, p. 2, emphasis in original) as critical preparation to teaching and learning in multicultural, multilingual, and radically inclusive spaces. Ultimately, if we are to meet the needs of our culturally and linguistically diverse students, we must develop new ways of affirming, engaging, and expanding the cultures, languages, and experiences of all members of the school community. In the words of Nero and Ahmad (2014), "To engage the vernacular in the classroom... is to risk disrupting [a] narrative that is inherently a problem" (p. 137). It is time we "brave up," and take the risks inherent in creating educational spaces that disrupt, defy, and reimagine what it means to teach, and learn, in increasingly diverse worlds.

\section{Notes}

1. All names are pseudonyms

\section{References}

Annamma, S. A., Boele, A. L., Moore, B. A., \& Klingner, J. (2013). Challenging the ideology of normal in schools. International Journal of Inclusive Education, 17(12), 1278-1294.

Aronson, B., \& Laughter, J. (2016). The theory and practice of culturally relevant education. Review of Educational Research, 86(1), 163-206.

Blankstein, A. M., Noguera, P., \& Kelly, L. (2016). Excellence through equity: Five principles of courageous leadership to guide achievement for every student. Alexandria, VA: ASCD.

Borrero, N., \& Sanchez, G. (2017). Enacting culturally relevant pedagogy: Asset mapping in urban classrooms. Teaching Education, 28(3), 279-295.

Charmaz, K. (2006). Constructing grounded theory. London, UK: Sage. 
Choi, Y. (2013). Teaching social studies for newcomer English language learners: Toward culturally responsive pedagogy. Multicultural Perspectives, 15(1), 12-18.

Creese, A., \& Blackledge, A. (2010). Translanguaging in the bilingual classroom: IA pedagogy for learning and teaching? The Modern Language Journal, 94(1), 103-115.

Creswell, J.W. (2007). Qualitative inquiry \& research design: Choosing among five approaches. Thousand Oaks, CA: Sage.

Dover, A. G. (2009). Teaching for social justice and K-12 student outcomes: A conceptual framework and research review. Equity \& Excellence in Education, 42(4), 506-524.

Dover, A. G. (2018). Your compliance will not protect you: Agency and accountability in urban teacher preparation. Urban Education. Advance online publication. https://doi.org/10.1177/0042085918795020

Dover, A. G., Henning, N., \& Agarwal-Rangnath, R. (2016). Reclaiming agency: Justice oriented social studies teachers respond to changing curricular standards. Teaching and Teacher Education, 59, 457-467.

Flores, N., \& García, O. (2013). Translanguaging across the bilingual continuum. In D. Little, C. Leung, \& P. Van Avermaet (Eds.), Managing diversity in education: Languages, policies, pedagogies (pp. 243-246). Bristol, United Kingdom: Multilingual Matters.

Fraise, N., \& Brooks, J. (2015). Toward a theory of culturally relevant leadership for school-community culture. International Journal of Multicultural Education, 17(1), 6-21.

Fránquiz, M. E., \& Salinas, C. S. (2011). Newcomers to the U.S.: Developing historical thinking among Latino immigrant students in a central Texas high school. Bilingual Research Journal, 34(1), 58-75.

Freire, P. (2005). Teachers as cultural workers: Letters to those who dare to teach (Expanded ed.). Boulder, CO: Westview Press.

Freire, P. (2013). Education for critical consciousness. New York, NY: Bloomsbury Academics.

Freire, J. A., \& Valdez, V. E. (2017). Dual language teachers' stated barriers to implementation of culturally relevant pedagogy. Bilingual Research Journal, 40(1), 55-59.

García, O., Woodley, H. H., Flores, N., \& Chu, H. (2012). Latino emergent bilingual youth in high schools. Transcaring strategies for academic success. Urban Education, 48(6), 798-827.

García, O., \& Seltzer, K. (2016). The translanguaging current in language education. In B. Kindenberg (Ed.). Flerspråkighet som resurs [Multilingualism as a resource] (pp. 19-30). Montreal, Canada: Liber. 
Gay, G. (2000). Culturally responsive teaching: Theory, research, and practice. New York, NY: Teachers College Press.

Gee, J. P. (2004). Situated language and learning: A critique of traditional schooling. New York, NY: Routledge.

Genesee, F. Linholm-Leary, K. Saunders, W., \& Christian, D. (2005). English language learners in U.S. schools: An overview of research findings. Journal of Education for Students Placed at Risk, 10(4), 363-385

Gorski, P. (2013). Reaching and teaching students in poverty: Strategies for erasing the opportunity gap. New York, NY: Teachers College Press.

Gutiérrez, K. D. (2008). Developing a sociocritical literacy in the third space. Reading Research Quarterly, 43(2), 148-164.

Heifetz, R. A., Grashow, A., \& Linksy M. (2009). The practice of adaptive leadership: tools and tactics for changing your organization and the world. Boston, MA: Harvard Business Press.

Hornberger, N. (2013). Foreword. In A. Blackledge \& A. Creese (Eds.). Heteroglossia as practice and pedagogy (pp. v-vii). New York, NY: Springer.

hooks, b. (2003). Teaching community: A pedagogy of hope. London, United Kingdom: Routledge.

Howard, T. C. (2014). Why race and culture matter in schools: Closing the achievement gap in America's classrooms. New York, NY: Teachers College Press.

Kohli, R., Picower, B., Martinez, A., \& Ortiz, N. (2015). Critical professional development: Centering the social justice needs of teachers. International Journal of Critical Pedagogy, 6(2), 7-24.

Ladson-Billings, G. (1995). Toward a theory of culturally relevant pedagogy. American Education Research Journal, 32(3), 465-491.

Lee, J. S. (2010). Culturally relevant pedagogy for immigrant children and English language learners. National Society for the Study of Education, 109, 453473.

Liggett, T. (2012). Deliberative democracy in English-language education: Cultural and linguistic inclusion in the school community. Democracy and Education, 22(2), 1-7.

Lopez, F. A. (2016). Culturally responsive pedagogies in Arizona and Latino students' achievement. Teachers College Record, 118(5), 1-42.

Mazak, C. M. (2017). Introduction: Theorizing translanguaging practices in higher education. In C. M. Mazak \& K. S. Carroll (Eds.). Translanguaging in higher education: Beyond monolingual ideologies (pp. 1-10). Bristol, United Kingdom: Multilingual Matters. 
Mitchell, K. (2012). English is not all that matters in the education of secondary multilingual learners and their teachers. International Journal of Multicultural Education, 14(1), 1-21.

Moll, L. C., Amanti, C., Neff, D., \& Gonzalez, N. (1992). Funds of knowledge for teaching: Using a qualitative approach to connect homes and classrooms. Theory into Practice, 31(2), 132-141.

Nero, S., \& Ahmad, D. (2014). Vernaculars in the classroom: Paradoxes, pedagogy, possibilities. New York, NY: Routledge.

Oyserman, D., Harrison, K., \& Bybee, D. (2001). Can racial identity be promotive of academic efficacy? International Journal of Behavioral Development, 25(4), 379-385.

Palmer, P. J. (2007). The courage to teach: Exploring the inner landscape of a teacher's life. San Francisco, CA: Jossey-Bass.

Paris, D., \& Alim, S. (Eds.) (2017). Culturally sustaining pedagogies: Teaching and learning for justice in a changing world. New York, NY: Teachers College Press.

Picower, B. (2011). Resisting compliance. Teachers College Record, 113(5), 1105-1134.

Rodríguez-Valls, F. (2009). Culturally relevant poetry: Creating Esperanza (hope) with stanzas. Multicultural Education, 17(1), 10-13.

Rodríguez-Valls, F. (2016). Pedagogy of the Immigrant: A journey towards inclusive classrooms. Teachers and Curriculum, 16(1), 41-48.

Salinas, C. Sullivan, C., \& Wacker, T. (2007). Curriculum considerations for latearrival high school immigrant students. Journal of Border Educational Research, 6(2), 55-67.

Sleeter, C. E. (2011). The academic and social value of ethnic studies: A research review. Washington, DC: National Education Association.

Stillman, J. (2011). Teacher learning in an era of high-stakes accountability: Productive tension and critical professional practice. Teachers College Record, 113(1), 133-180.

Suárez-Orozco, C., Pimentel, A., \& Martin, M. (2009). The significance of relationships: Academic engagement and achievement among newcomer immigrant youth. Teachers College Record, 111(3), 712-749.

Valenzuela, A. (2016). Growing critically conscious teachers: A social justice curriculum for educators of Latino/a youth. New York, NY: Teachers College Press.

Vygotsky, L. V. (1986). Thought and language. Boston, MA: The MIT Press.

Wei. L. (2018). Translanguaging as a practical theory of language. Applied Linguistics, 39(1), 9-30, 
Wiemelt, J., \& Welton, A. (2015). Challenging the dominant narrative. International Journal of Multicultural Education, 17(1), 82-101.

Yeon Kim, H., \& Suárez-Orozco, C. (2015). The language of learning: The academic engagement of newcomer immigrant youth. Journal of Research on Adolescence, 25(2), 229-245.

\section{Author Contact}

Alison Dover, adover@fullerton.edu, Secondary Education Department, California State University Fullerton, 2600 Nutwood Ave., Fullerton CA, U. S. A. 92831

Fernando Rodríguez-Valls, frodriguez-valls@fullerton.edu, Secondary Education Department, California State University Fullerton, 2600 Nutwood Ave., Fullerton CA, U. S. A. 92831 